\title{
Práticas pedagógicas em dança na Escola Estadual General Edson Figueiredo
}

\author{
Prácticas pedagógicas en danza en la Escola Estadual General Edson \\ Figueiredo \\ Pedagogical pratices in dance at Escola Estadual General Edson \\ Figueiredo
}

\author{
Neila Baldi ${ }^{1}$ \\ Bruna Potrich ${ }^{2}$ \\ Oneide Alessandro Silva dos Santos ${ }^{3}$
}

\begin{abstract}
Resumo
Este trabalho tem como objetivo apresentar e discutir práticas pedagógicas em Dança realizadas na Escola Estadual General Edson Figueiredo, no município de Santa Maria/RS. As ações foram desenvolvidas em turmas de $6^{\circ}$ e $7^{\circ}$ ano do ensino fundamental, como parte das atividades do Programa Institucional de Bolsas de Iniciação à Docência (PIBID), Subprojeto Dança, da Universidade Federal de Santa Maria (UFSM). Tendo como eixos norteadores: Consciência Corporal, Paisagens Sonoras; Criação e Composição e Qualidades de Movimento, os bolsistas sistematizaram propostas para atividades em sala de aula. Este processo se deu de forma colaborativa, envolvendo coordenação, supervisão e estudantes pibidianos. Foi possível perceber que o trabalho contribuiu para os alunos realizassem novas aprendizagens corporais, ampliando o seu repertório de movimento e percebendo a dança como possibilidade criativa.
\end{abstract}

Palavras-Chave: Dança; Escola; Práticas Pedagógicas.

\section{Resumen}

Esta investigación académica tuvo como objetivo presentar y discutir prácticas pedagógicas en Danza conducidas en la Escola Estadual General Edson Figueiredo, en el municipio de Santa Maria, estado de Río Grande del Sur. Las acciones fueron desarrolladas en grupos de $6^{\circ}$ y $7^{\circ}$ años de la enseñanza fundamental, como parte de las actividades del Programa Institucional de Bolsa de Iniciação à Docência (PIBID), Subproyecto Danza, de la Universidad Federal de Santa Maria (UFSM). Los ejes orientadores fueron: Consciencia Corporal, Paisajes Sonoros; Creación y Composición y Cualidades del Movimiento, y los becarios sistematizaron propuestas para actividades en clase. Este proceso ocurrió de forma colaborativa, involucrando coordinación, supervisión y estudiantes del PIBID. Fue posible percibir que el trabajo contribuyó a los alumnos a realizar nuevos aprendizajes corporales, ampliando su repertorio de movimiento y percibiendo la danza como una posibilidad creativa.

1 Doutora em Artes Cênicas; Universidade Federal da Bahia - UFBA; Salvador, Bahia; Coordenadora do Programa Institucional de Bolsas de Iniciação à Docência, Subprojeto Dança; Universidade Federal de Santa Maria - UFSM; Brasil; neila.baldi@ufsm.br

2 Graduada em Dança Licenciatura; Bolsita Capes/PIBID, Universidade Federal de Santa Maria; Santa Maria; Rio Grande do Sul, Brasil; brunaleticiapotrich@gmail.com

3 Graduando em Dança Licenciatura; Bolsista Capes/PIBID; Universidade Federal de Santa Maria; Santa Maria; Rio Grande do Sul, Brasil;fio.sb.14@hotmail.com 
Palabras claves: Danza; Escuela; Prácticas pedagógicas.

\begin{abstract}
This academic paper aims to present and discuss pedagogical practices in Dance performed at Escola Estadual General Edson Figueiredo, located at Santa Maria, state of Rio Grande do Sul. The actions were conducted with 6th and 7th grades elementary school students, as part of the Programa Institucional de Bolsa de Iniciação à Docência (PIBID), Subproject Dance, by Federal University of Santa Maria (UFSM). The main guidelines included: Body Consciousness, Soundscapes; Creation and Composition and Qualities of Movement, and scholars systematized proposals for activities in classroom. This process is collaborative and involves coordination, supervision and students of PIBID. It was possible to observe that this work contributed to students realize new corporal learnings, amplifying their repertoire of movement and perceiving dance as a creative possibility.
\end{abstract}

Keywords: Dance; School; Pedagogical Practices.

\title{
1. Introdução
}

O presente artigo visa apresentar as ações desenvolvidas pelo Programa Institucional de Bolsas de Iniciação à Docência (PIBID), subprojeto Dança, da Universidade Federal de Santa Maria (UFSM), desenvolvidas na Escola Estadual General Edson Figueiredo, no ano de 2017, em turmas de 6 e 7 anos do ensino fundamental.

O PIBID Dança surgiu em 2014 em decorrência da criação do curso de Dança Licenciatura da UFSM e tinha previsão de execução até fevereiro de 2018 - com possibilidade de renovação por mais seis meses. Até dezembro de 2017 contava com uma coordenadora e uma professora-colaboradora, uma supervisora vinculada às duas escolas de atuação do programa e cinco bolsistas graduandos em Dança. Destes, quatro bolsistas estavam com turmas fixas trabalhando conteúdos específicos da Dança na disciplina de Artes e uma bolsista era responsável pelas oficinas e projetos concomitantes nas escolas, tanto com professores e alunos. Cada turma atendida tem entre 20 a 25 alunos.

As atividades do PIBID Dança tinham como público-alvo estudantes dos anos finais do ensino fundamental $\left(6^{\circ}\right.$ ao $9^{\circ}$ ano) e eram desenvolvidas em duas escolas de Educação Básica Pública, em Santa Maria: Escola Municipal Vicente Farencena, e a escola aqui descrita nas práticas - Escola Estadual General Edson Figueiredo. As aulas ocorriam uma vez por semana, com duração de um período dentro da disciplina de Artes - ou seja, pouco tempo para sintetizar os conteúdos, reflexões e avaliações.

Desde a sua criação até os dias atuais, o PIBID Dança atuou com reuniões semanais, além da inserção na escola, onde são discutidas as questões pertinentes ao fazer docente, 
sistematizadas atividades e propostas a serem realizadas nas escolas. Neste período, desenvolveu eixos de ação que têm norteado a preparação das aulas: Consciência Corporal, Paisagens Sonoras; Criação e Composição e Qualidades de Movimento. Estes eixos foram baseados no Livro "Teatro e Dança" (FERREIRA, FALKEMBACH, 2012), no qual as autoras introduzem temáticas do teatro e da dança na escola e possibilidades de ideias para um projeto próprio construído em consonância com a teoria e a prática da sala de aula. A partir dos eixos elaborados pelo PIBID Dança construímos, de forma compartilhada, planejamentos, métodos e avaliações para trabalhar com os alunos no processo de ensino e aprendizagem em dança.

O trabalho aqui apresentado foi realizado a partir dessas premissas e tiveram como forma de avaliação, para a reflexão sobre o processo, o feedback dos alunos, bem como as observações dos pibidianos e as discussões nas reuniões semanais. Este texto apresenta propostas trabalhadas em aula, dialogando com reflexões feitas a partir das experiências de iniciação à docência na escola.

\section{Reflexões sobre o ensino da dança na escola}

Mas afinal o que é a dança? Existe dança no currículo escolar? O que se ensina nas aulas de dança na escola e como? São alguns questionamentos cotidianamente apresentados aos professores que chegam à escola e precisam fazer um panorama sobre as linguagens, conceitos e pré-conceitos existentes pelos alunos. A dança ao longo da história é manifestada de diferentes formas, desde aquela realizada em casa pela criança ou adolescente, assistindo televisão, até a executada no teatro. Neste sentido, muitas vezes não encontramos definições sólidas ou imutáveis, mas alguns parâmetros para pensar e trabalhar a dança na escola. Entre estes, podemos falar em dança como "expressão", que é ligada aos indivíduos e aos grupos sociais, e a dança como "forma" tal como coreografias, danças que são difundidas e reproduzidas como prontas (MARQUES, 2012).

Segundo Strazzacappa (2004, p. 184), “A escola formal nunca foi um espaço privilegiado para o ensino de dança. Tradicionalmente, as artes plásticas e a música imperavam neste ambiente institucional como conteúdo da disciplina educação artística." Ainda existem muitos entraves no que diz respeito ao conhecimento sobre dança como conteúdo escolar. Tais falhas estão arraigadas ao pensamento de que a dança é um “dom”, um "talento" que nem todos têm essa possibilidade ou ao de que a dança na escola deve ser o aprendizado de um gênero: balé, danças populares, hip hop. Muitas vezes, esses pensamentos 
fazem com que a dança se torne sem sentido na vida dos alunos e no currículo escolar, não levando em conta fatores históricos, sociais e culturais primordiais para que tanto alunos, professores e escolas desempenhem um papel fundamental na educação dos corpos, na compreensão da criatividade, dos processos artísticos, nas relações entre corpo, dança e sociedade, como também na apropriação crítica, consciente e transformadora dos conteúdos específicos da dança (BRASIL, 1997).

Ora, para Freire (2013), compreender a educação como uma forma de intervenção no mundo é resultado de uma educação emancipadora que forneça subsídios para um pensamento crítico e criativo. Significa fundamentalmente o pensamento por si e em si, do seu lugar na história e na vida em sociedade. Freire (2013) dizia que a educação é uma forma de intervenção no mundo. Neste sentido, o ensino da dança pode possibilitar uma experiência humana ligada inevitavelmente na produção de conhecimento sobre si e do outro, sobre criatividade, autonomia e dialeticamente de intervenção no mundo. A dança pode atuar como uma ferramenta de desconformidade nos modos operantes da educação tradicional, por isso é necessária.

Para Marques (2005, p. 26), "ao contrário de uma visão histórica ingênua de que a dança não passa de 'uns passinhos' a mais ou a menos na vida das pessoas, hoje não podemos mais ignorar o papel social, cultural e político do corpo em nossa sociedade.” A dança como linguagem é fundamental à educação, uma área privilegiada para que possamos trabalhar, discutir e problematizar diferentes realidades, experiências dos alunos, das escolas e dos professores.

Desta forma, a autora compreende que existem especificidades da dança, que não são encontradas em outros componentes curriculares ou em outras linguagens artísticas. Para ela, os conteúdos específicos da dança são textos, contextos e subtextos (MARQUES, 1997). Segundo a autora, os subtextos da dança são aspectos dos movimentos e suas estruturas, perceber, experimentar e entender os nossos corpos, conhecendo as partes, dinâmicas, espaços que ocupam as ações de cada um ligadas à consciência corporal ou conhecimento do corpo. Por sua vez, os contextos são os elementos históricos, sociais, culturais que a dança se insere atreladas à história, estética, apreciação e crítica da dança, são os saberes sobre dança. E, por último, os textos são o conhecimento direto sobre dança, repertórios de dança, composição, criação, improvisação, visando uma educação do/pelo movimento (MARQUES, 1997). 
Foi a partir destes saberes sobre dança na escola que construímos os eixos norteadores do PIBID Dança, buscando autores que estudam a temática para configurar nosso "jeito" de ensinar a dança, atentados para as realidades educacionais que vivenciamos no cotidiano, entendendo que precisamos considerar o contexto em que estamos inseridos. Neste sentido, deveríamos ser maleáveis, de maneira em que pudéssemos refletir e rever os modos de fazer-pensar dança para cada situação, impulsionados “[...] pela busca da dança 'de cada um', [...] a busca por transformar um modo particular de mover, em dança" (ROCHA, 2012, p.37).

Estes eixos que norteiam nosso trabalho de iniciação à docência resultaram na elaboração de um livro didático titulado "Qual é a sua dança?: Dança para crianças $e$ adolescentes" lançado em 2017. Neste livro, trazemos a sistematização de quatro anos de trabalho do grupo na Universidade, com as escolas Edson Figueiredo e Vicente Farencena, dando ênfase às atividades desenvolvidas com os alunos. Acreditamos na importância desse material para que sirva como aporte para professores que trabalham com dança. Ou seja, consideramos que este foi o nosso modo de chegar até a escola e possibilitar um ensino significativo da nossa área de conhecimento.

O ensino da dança no Brasil é legalmente regulamentado a partir de 1997 por meio dos Parâmetros Curriculares Nacionais (PCNs), que incluíram a dança como conteúdo a ser trabalhado dentro da disciplina de Artes. Porém, sabemos que a realidade vai contra essa idealização. Por meio do nosso trabalho, descrito abaixo, pretendemos construir nosso espaço, mostrando a importância da nossa área de conhecimento, para que esteja presente tanto em ambientes informais, como formais. Com nosso material, pretendemos também ajudar profissionais da área a trabalhar com a dança na escola, em uma perspectiva para além de gêneros de dança, de coreografias prontas e outros clichês tão presentes ainda neste ambiente.

\section{A estruturação dos conteúdos e as práticas em dança}

Ferreira e Falkembach (2012, p. 60) lembram que "toda ação educativa é construída a partir de uma abordagem que agrega: como se vê o mundo, como se vive no mundo e a forma como se quer transformá-lo (ou não)". E que, assim, uma aula de dança pode tanto construir corpos dóceis como transgressores. Desta forma, segundo a autora, "a dança em coerência a uma educação não opressora, tem trabalhado com o conceito de corpo a partir de uma perspectiva interdisciplinar, que o percebe como algo que não é fixo e que está em constante construção." 
A partir desse entendimento, propomos o eixo Consciência Corporal, que abarca o conhecimento sobre partes, totalidade e reconhecimento do corpo, de si e do colega. A ideia é refletir sobre suas limitações, subjetividades e possibilidades de mover-se, pensar e criar. Entendemos a importância de se trabalhar a corporeidade em sala de aula de forma que os alunos se entendam e assim se vejam como identidades móveis em contínua trans(formação), tendo em vista que passamos por mudanças durante toda nossa vida.

Neste eixo, desenvolvemos aulas propondo que os alunos reconhecessem suas partes do corpo, começando do pé até a cabeça, com movimentos mais fragmentados para possibilitar um diferente olhar sobre se conhecer. Propusemos que verificassem suas limitações, bem como as facilidades para cada movimento. Também indicamos exercícios de tocar os pés, dedos, massagens etc, que procuravam identificar partes despercebidas no cotidiano. Assim como prestar atenção à respiração e concentrar-se durante a execução de algum movimento. Verificamos que para muitos alunos foi desafiador perceber seu próprio movimento e conhecimento sobre si. Mas não podemos esquecer que, de acordo com Lenira Rengel (2008), o professor deve ser o mediador entre os conhecimentos que o aluno vai construindo no cotidiano escolar, estimulando-o a ser quem é e a se conhecer:

\begin{abstract}
Devemos, nós educadores, olhar para a criança ou jovem com idade que tem dois, cinco ou quinze anos. Sempre se encara a criança como um "vir a ser", um adulto em miniatura. Pense em algo muito simples, que é o modo como à maioria das crianças é vestida. Elas parecem mesmo "adultas em miniatura". Triste metáfora, a da criança se "achar" adulta. É preciso percebê-la como alguém que "é", até aquele momento de seu processo de vida, com seus dois ou oito anos, etc. Claro que queremos que as crianças cresçam, tornem-se adultos, vivam. Todavia, é preciso respeitar a pessoa com a idade que ela tem como ela é. Em geral, nas Escolas e nas famílias, as crianças, os adolescentes ficam a espera do ingresso no mundo adulto. Isto é muito prejudicial! Usamos expressões como: "ele não consegue", "não tem maturidade". Não consegue, não tem maturidade em relação a que, a quem? Aos adultos? Bom, convenhamos que este tipo de comparação seja, no mínimo, autoritário, em desacordo com o desenvolvimento infanto-juvenil, e nega o tempo real, isto é, o tempo que está em curso no momento. (RENGEL, 2008, p. 11).
\end{abstract}

A forma de ensino tradicional dificilmente permite tais experiências: nossos alunos não estão acostumados a parar e olhar para si, observar o que seu corpo pede ou quer, por isso essas experiências simples às vezes parecem tão complexas para eles. Nas aulas de dança exploramos diferentes dinâmicas no chão para desacomodar o repertório de movimentação dos alunos, convidando-os a caminhar de pé descalço, em diversas direções, níveis e tempos, 
dessa forma buscamos oportunizá-los a ter diferentes práticas corporais e, assim, diversas vivências.

No eixo paisagens sonoras foram desenvolvidas ações baseadas no ritmo, pausa, métrica e percussão corporal. Quais sons o corpo produz? Existe um ritmo interno no nosso corpo? E um externo? São algumas perguntas que conduzem pensar as paisagens sonoras que se produzem no cotidiano. Outros elementos podem ajudar: pensar a dança em diferentes ritmos além dos regulares, ou dançar sem uma música tentando escutar seu ritmo interno, reproduzir e criar músicas com o corpo (palmas, batidas em diferentes partes, a voz). Desta forma o aluno vai gerando expressividade, que está diretamente ligada a como o corpo se percebe, se movimenta: o simples andar precisa de um ritmo e assim as aulas de dança se apresentam como uma proposta coerente para assumir e construir estes conhecimentos nos alunos (FERREIRA; FALKEMBACH, 2012).

Acreditamos ser importante levar essa diversidade de saberes sobre a dança, tentando com isso fugir das visões tradicionais associadas à dança de ser só coreografada, não como modo de diminuí-la. Neste sentido, oferecemos outros formatados, criações e variações aproximando aos alunos a fruição estética da arte que é a dança.

Trabalhamos a partir de sonoridades que os próprios alunos produziam em improvisação na aula. Uma das atividades realizadas foi a solicitação de que cada aluno produzisse um som (com o corpo) e depois o colega, em sequência na roda. No final, juntamos todos os sons, produzindo uma percussão corporal. Nesta criação, foram explorados sons, ruídos, batidas, sussurros. É interessante pensar que além da criação de sons isso também cria movimentos, apesar de não intencionais, esses movimentos provocam visualidades, gerando possibilidades de dançar e fazer música de forma simultânea. Marques (2011, p. 35) diz que: “Ao propor a educação dos corpos lúdicos em nossas salas de aula de dança, propomos também a possibilidade de que esses corpos sejam capazes de criar e de recriar suas danças e, assim, a sociedade."

A criação e composição, terceiro eixo norteador, propôs atividades que articulam e dão ênfase às ações de processos criativos, interpretativos e dos códigos de dança, sejam eles tradicionais ou contemporâneos. Possibilidades de criar a própria dança, ou em conjunto com os colegas e professores, utilizando diferentes recursos cênicos, musicais, visuais e de movimentação para então estimular a criatividade e autonomia dos alunos. Isto por que: 
Uma coreografia não é uma sequência de movimentos realizados por um grupo da mesma maneira. Numa coreografia, cada dançarino pode ter sua sequência individual. Pode, também, não ter uma sequência definida (FERREIRA, FALKEMBACH, 2012, p.116).

Aqui novamente nos deparamos com esse contraste do que se consagrou popularmente como dança, como coreografia. Ao chegar à escola por vezes encontramos resistência por parte dos alunos, que possuem essa visão de dança. Então, quando chegamos com uma proposta de conhecer o corpo e criar sua própria dança, por vezes sofremos com a não aceitação ou com o preconceito criado. No entanto, ao longo do trabalho, aos poucos vamos movimentando e mudando essas ideias. É nosso papel de artistas-docentes trabalhar para que esses conceitos e visões antigas e ultrapassadas sejam renovados e para que assim tenhamos mais liberdade de nos movimentar, pensar-fazer a dança nesse ambiente formal de ensino.

A criação foi apresentada aos alunos durante todos os eixos, por meio do incentivo da autonomia e elaboração de movimentos próprios e/ou em duos, trios e grupo na composição de seus repertórios. Entendemos que nem sempre os alunos estão dispostos a se expor, portanto a criação coletiva é um caminho de início que se torna mais confortável e mais seguro para quem nunca teve esse contato com a criação de dança. Esta realidade encontrada na escola vai ao encontro das reflexões feitas por Leal (2012, p. 57-58):

\footnotetext{
Depois dessa vivência e questionamentos, os alunos começaram a compreender uma requisição recorrente em aula: errar. A ansiedade em acertar e a dicotomia entre certo e errado é, em minha experiência docente, um dos maiores obstáculos dos alunos, pedagogicamente e metodologicamente, trabalhamos com a sensação dos movimentos, a busca de princípios de movimento encontrados em cada estrutura corporal, a criação coletiva, a tematização de movimentos, a contaminação, entre outros recursos, que valorizam o indivíduo, reconhecendo nele a diferença e, no reconhecimento da diversidade, construímos o coletivo.
}

Entre as propostas apresentadas, desenvolvemos aulas de criação baseadas nos modos de se mover dos animais, tematizando assim os movimentos: sorteamos um animal para cada aluno com o objetivo que eles criassem a movimentação do mesmo. Depois solicitamos aos alunos que trouxessem imagens, figuras dos animais, para, a partir do concreto, experimentar a criação de sequência coreográfica deles, finalizando com uma mostra para a turma de cada um individualmente. Marques (2007, p. 32) ressalta a importância dos momentos de improvisação e/ou criação: segundo ela, esses processos “[...] 
permitem aos alunos experimentar, sentir, articular e pensar a arte como criadores e sujeitos do mundo."

O último eixo - qualidades do movimento - se baseou nas relações estabelecidas do corpo que dança, do sujeito que se movimenta tendo como foco os quatro fatores de movimento propostos pelo estudioso do movimento Rudolf Laban: espaço, tempo, peso e fluência. Segundo Ferreira e Falkembach (2012, p. 90):

\begin{abstract}
Qualidade do movimento não é medida de valor, por exemplo, se o movimento é bom ou ruim, benfeito ou malfeito. A qualidade de um movimento significa o tipo de movimento: característica, propriedade. Uma caminhada realizada por pessoas diferentes terá diferentes qualidades. Observe as pessoas na rua e verá enorme a variação de qualidade de movimento de caminhar: acelerado, lento, pesado, flutuante, tenso, relaxado, duro, eufórico, cauteloso, preguiçoso, vigoroso, etc. A qualidade do movimento, o "como" do movimento, está realizada com a intenção do mesmo.
\end{abstract}

Ao levar essa estruturação do movimento para sala de aula, notamos que os alunos passam a observar a dança de outros modos, não é mais só a coreografia, mas há um estudo das qualidades empregadas em cada métrica do movimento que agora pode ser feito, e isso se torna bastante significativo para eles, e coloca a dança em outro patamar, do pensar-fazer dança.

Neste último eixo trabalhamos com base nas proposições de Lenira Rangel (2008) sobre as temáticas do movimento. A autora sistematiza saberes sobre como utilizar o Sistema Laban em diferentes etapas do ensino, propondo modos de aplicação. Fundamentados nisso, criamos nossos próprios temas de movimento para trabalhar em sala. Uma das temáticas abordadas foi para trabalhar peso, fluência e espaço com os alunos a partir dos modos de andar, junto com o grupo, em duos, como um trem, sozinho, deslizando, flutuando, muito lento.

Acreditamos que os quatro eixos propostos permitiram que trabalhássemos os conteúdos de dança elencados por Marques (1997). Além disso, nos eixos e atividades desenvolvidas durante o semestre, buscamos trabalhar integrando os alunos às propostas. Tendo como base suas experiências, coisas que eles gostassem ou que fossem da sua realidade, para assim, explorar ainda mais seu repertório de movimentos, no intuito de incluir tanto nossos conhecimentos como os deles na construção das aulas. Para Freire (2013, p. 32), o ensino deve respeitar os saberes dos educandos, sobretudo das classes populares e das suas 
realidades: "Por que não estabelecer uma 'intimidade' entre os saberes curriculares fundamentais aos alunos e a experiência social que eles têm como indivíduos?"

A avaliação das aulas se deu por meio da observação diária na participação, do envolvimento, colaboração e realização das atividades propostas. Também nos baseamos no feedback dos alunos ao final de algumas aulas, procurando identificar o que funcionou e o que não. Os diálogos com a professora da turma também foram essenciais para adequar as propostas para a turma.

\section{Considerações finais}

Desta maneira, a partir dos eixos, as aulas foram planejadas e executadas levando em consideração as particularidades e singularidades da escola, alunos e professores. Durante os encontros semanais do PIBID Dança, realizamos reflexões sobre a própria prática e planejamento, dialogando com vertentes teóricas e análises dos colegas do grupo, fundamentais para a construção da ação docente e trocas de aprendizados. Cada um do grupo contribuiu com reflexões, críticas e referenciais para somar e agregar a prática de ser um professor de dança.

As reflexões aqui apresentadas são resultados dos relatórios diários de cada aula, dos planejamentos semanais e encontros com os demais colegas do grupo. Em suma, as contribuições da professora responsável pela disciplina e feedback dos alunos foram elementos essenciais para a construção deste texto como as nossas reflexões teóricas sobre a prática.

Desta forma, é possível perceber que todo o processo desenvolvido pelo PIBID Dança se deu de forma colaborativa. O trabalho em grupo permitiu que considerássemos diversos pontos de vista e produzíssemos conhecimento compartilhado, de modo a construirmos juntos nossos saberes sobre a prática docente. No "[...] diálogo entre coordenadores, supervisores e licenciandos, há um processo de enriquecimento compartilhado, com impactos positivos tanto nos cursos de formação como nas escolas." (NEVES, 2012, p. 365 apud FERNANDES; SISLA; NASCENTE, 2016, p. 292)

Por outro lado, percebemos que o nosso trabalho contribuiu para que os alunos realizassem novas aprendizagens corporais, ampliando seus repertórios de movimento e pudessem enxergar a dança sob outros prismas.

Acreditamos ainda que, com este trabalho, estamos apresentando à comunidade escolar a dança como área de conhecimento, possibilitando que todas as pessoas envolvidas - 
alunos e professores das escolas - consigam compreender as especificidades da dança como Arte e a importância de sua inserção na escola.

\section{Referências}

BRASIL. Parâmetros Curriculares Nacionais: arte. Secretaria de Educação Fundamental. Brasília: MEC/SEF, 1997.

FERNANDES, Jarina Rodrigues. SISLA, Heloisa Chalmers. NASCENTE, Renata Maria Moschen. Pibid como espaço de formação docente. Educação. Porto Alegre, v. 39, n. 2, p. 291-301, set-dez 2016.

FERREIRA, Taís. FALKEMBACH, Maria Fonseca. Teatro e Dança nos anos iniciais. Porto Alegre: Mediação, 2012.

FREIRE, Paulo. Pedagogia da autonomia: saberes necessários à prática educativa. 46. ed. Rio de Janeiro: Paz e Terra, 2013.

LEAL, Patrícia. Errática: percursos artístico-pedagógicos. In: GONÇALVES, Thaís; BRIONES, Héctor; PARRA, Denise; VIEIRA, Carolina. (Org.). Docência artista do artista docente: Seminário Dança Teatro Educação. Fortaleza: Expressão Gráfica e Editora, 2012. p. $50-63$.

MARQUES, Isabel. Interações: crianças, dança e escola. São Paulo: Blucher, 2012.

. Notas sobre o corpo e o ensino de dança. Cadernos Pedagógicos, Lajeado, v. 8, n. 1, p. 3-36, 2011.

Ensino de dança hoje: textos e contextos. $4^{\mathrm{a}}$ Ed. São Paulo: Cortez, 2007.

Dançando na escola. $2^{\mathrm{a}}$ Ed. São Paulo: Cortez, 2005.

Dançando na escola. Revista Motriz, Rio Claro, v. 3, n. 1. jun./1997.

RENGEL, Lenira. Os temas do movimento de Rudolf Laban. São Paulo: Annablume, 2008.

ROCHA, Thereza. Por uma docência artista com dança contemporânea. In: GONÇALVES, Thaís; BRIONES, Héctor; PARRA, Denise; VIEIRA, Carolina. (Org.). Docência artista do artista - docente: Seminário Dança Teatro Educação. Fortaleza: Expressão Gráfica e Editora, 2012. p. 32-49.

STRAZZACAPPA, Márcia. Reflexões sobre a formação profissional do artista da dança. In: PEREIRA, Roberto. SOTER, Silvia (org). Lições de Dança 4. Rio de Janeiro: UniverCidade, 2004. p.175-193. 